\title{
The Cultural Diaspora Perspective on Translation Studies
}

\author{
LIU Yan-shi \\ Sichuan University of Arts and Science, Dazhou, China
}

\begin{abstract}
Along with the process of globalization, diaspora has already become an eye-catching cultural phenomenon. More people cross borders of nations, leave their homeland and live in new homes, but they still maintain the characteristics of native culture and convention. The cultural turn in translation studies offers the best chance to understand more about the complexities of textual transfer and the patterns of cultural interaction. By virtue of this mode of cultural interaction, this paper has analyzed the translation practice and translation strategies from the cultural diaspora perspective, to deeply understand the relations between translation and culture beyond linguistic analysis. As in-between culture identity translators may re-examine two cultures with different eyes to find the intersection of two cultures and gain a balanced point. This move requires translators who play the role of intermediaries between cultures, to select the heterogeneous reconstruction, so as to achieve the intercultural communication in the translation activity.
\end{abstract}

Keywords: diaspora theory, culture, heterogeneous reconstruction, translation strategy

\section{Introduction}

The term "diaspora" from Greek $\delta 1 \alpha \sigma \pi \mathrm{o} \alpha$, which means "scattering, dispersion, sowing over", refers to a scattered population with a common origin in a smaller geographic area. Diaspora can also refer to the movement of the population from its original homeland and usually its people have a hope or at least a desire, to return to their homeland, if the "homeland" still exists in any meaningful sense. Nowadays, diaspora often refers to populations, such as members of an ethnic or religious group, which originated from the same place but dispersed to different locations. Although a nation of people left the homeland to the overseas life, they always maintained the characteristics of native culture. Diaspora may result in a loss of nostalgia for a single home as people "re-root" in a series of meaningful displacements. In other words, diaspora contains a desolate feeling and a sense of loss. It is not passive, lost, but of more joy in life, full of new vitality.

Globalization produces "an untotalizable totality which intensifies binary relations between its parts - mostly nations, but also regions and groups, which, however, continue to articulate themselves on the model of national identities" (Jameson, 1998, p. xii). It not only breaks the constraints of regional and national boundaries by spreading material and spiritual products, which may affect every corner of life on earth, but also includes the people with cultures moving across the borders. With the accelerating and deepening process of globalization, more and more people are crossing borders, to leave their native land and then live in new homes. They have to examine the new culture with their own maternal cultural value. As they have special identities,

LIU Yan-shi, associate professor, master, School of Foreign Languages, Sichuan University of Arts and Science. 
they will re-examine maternal culture with a diaspora angle. Thus, the diasporic issue is becoming a focus with its generalization and regulation, as an eye-catching cultural phenomenon.

As one diaspora writer has ever put, "culture is just like the wind, as the wind has no borders, and also no desire for any centre, one centre will become a tornado". One nation lives not only in a natural world, but also in a space of culture. The important feature of the space is to constantly pursue heterogeneous culture for its own enrichment and development. This feature shows that any individual group culture must have a certain relation with other ethnic cultures for its further growth, in other words, an isolated cultural space cannot exist. Any kind of culture can cross national and language boundaries to spread and show the heterogeneous cultural connotation in an outward "other" space, to promote the growth of national culture in foreign territories or countries. So to say, this feature of "national culture crossing the boundaries" is a prerequisite for cultural exchange, also an internal driving force of cultural innovation. Diaspora is naturally involved in the process of crossing the boundaries to disperse heterogeneity and enrich self.

Translation is about language, but translation is also about culture, for the two are inseparable. As Tymoczko and Gentzler (2002) pointed out, translation is implicit in process of cultural transformation and change. Translation involves power structures of appropriation by the center, but also acts of resistance through translation from the local and the indigenous. Translation is the transformation of the Self into Otherness, in order to become aware of one's own alienated Otherness, by temporalizing the sameness of the Self. Translation is regarded as contact, interaction, and even collision between two languages and cultures that are mutually transformed in this relationship. The cultural turn in translation studies offers the best chance to understand more about the complexities of textual transfer and the patterns of cultural interaction. In the context of globalization, "translational turn" in cultural studies implies that translation is a type of cultural communication and interpretation. So the great mission of translators is to transmit cultures and enable each culture to articulate its own distinctiveness. Professor SUN Yi-feng (2004) wrote an essay on cultural mission of diaspora translators, in which he introduced the concept of cultural diaspora, so that the field of translation studies was expanded. Above all, diaspora provides a new and broader cross-cultural perspective.

\section{Translation Practice From Diaspora Perspective}

From the diaspora perspective, re-understanding of translation practice will have important guiding significance for the translator to carry on translation activities. The main factors that occupy an important subject status in translation activities include the translator, the original text, translations, and readers. In this paper, cultural translation does not merely denote a particular kind of translation strategy, but rather a perspective on translations that focuses on their emergence and impact. In the following, by way of the mode of cultural interaction, the author will focus on analyzing the translator, translations, and readers respectively from the diaspora perspective.

\section{The Translator and Cultural Diaspora}

The traditional view on culture is the binary opposition of "self" and "other", which makes the translator's cultural identity and cultural orientation predefined statically. A more fundamental criticism of the concept of cultural translation questions the very existence of cultures. Cultural descriptions based on this conception, participated in constructing the alleged primitivism of non-western peoples by representing them as radically 
separate and sealed off from the describing Western societies. Therefore, the translator usually has to adopt the domestication translation strategy to minimize the foreignness of the target language and conform to its culture values. In some degree, the translator as cultural mediator shoulders cultural mission to highlight the cultural identity of the target language. Prof. SUN Yi-feng (2004) put forward the concept of diasporia translator who completes cultural mission in cultural exile, and is located in a "third cultural status" between the "alienation" and "domestication" cultures. As Wolf (2002) put, in this view, translation is not an interchange between discrete wholes but a process of mixing and mutual contamination, and not a movement from source to target but located in a "third space" beyond both, where conflicts arising from cultural difference and the different social discourses involved in those conflicts are negotiated. If a translator can effectively play the role of translation and successfully accomplish his mission, from the cultural diaspora angle, he may manage to have a unique translational mode in coordinating cultural relations and dealing with cultural differences, so as not to resort to the local strategy that refers to rational cultural mediation ensuring successful communication of cultural value.

Culture becomes visible only when differences appear. To some degree, the translator as the cultural mediator refers to a person who facilitates communication, understanding, and action between persons or groups who differ with respect to language and culture. His role is to establish and balance the communication between cultural groups. The translator must be able to participate to a certain extent in both cultures. No wonder that Vermeer (1994), a German translation theorist, believes that the translator must be bicultural, and another German theorist, Snell-Hornby (1994) compares the translator to "an intercultural expert".

To select one from a series of viable target texts, the translator as the mediator will need to mindshift cultural orientation (Taft, 1981). From the "third perceptual position", disassociated from both the contexts of the source text and from those of the virtual target text, the translator can "objectively" manipulate the text. In the face of two cultures, the translator must shoulder the sacred mission of cultural dissemination. In translating, it is inadvisable to overuse the strategy of domestication translation; likewise, it is impracticable to adopt the strategy of alienation translation excessively. As an American translation theorist, Robinson (1995) said, "Translation does not only show differences, but differences beyond" (p. 153). Therefore, in the name of showing differences and dispersing the heterogeneity, to overuse the strategy of alienation translation goes against the implication of diaspora.

From the diaspora perspective, the translator, in the process of translation, does not mechanically express or lively transplant the cultural difference to the target language readers, but ensures that the heterogeneous cultural factors can grow and regenerate in an exotic environment, in the dissemination process. Foreignizing practices which seek to send the reader abroad will be considered to be a highly desirable cultural intervention. This is to be achieved by making the readers aware of the differences inherent in the foreign text, by an estranging or heterogeneous translation style designed to highlight the foreign identity of the source text. The translator is to help the readers of target language to accept foreign culture and its values, to reproduce those images and associations in their minds as possible as one can. Then, the target language reader's confusion caused by cultural differences will gradually diminish and finally disappear, with the more familiarity with the original national culture. Therefore, a translator as a diaspora person who insists on national culture, should not only maintain differences in his own national culture, but also dare make use of these differences to re-create in another culture, striving to achieve the cultural translatability, and help shape the cross-national characteristics. 
Walter Benjamin (2012) suggested that one task of translation is to show the translatability of the original text. So, how to understand "translatability"? Translatability refers to communication between different human cultures and different spiritual phenomenon. Only in the process of cross-national communication will national identity be shown. At the same time, he also pointed out that the original translatability exists only for competent translators. Then, what does a competent translator refer to? A competent translator must know that translation is regeneration of the original because it participates in the "afterlife" of the source text. That is to say, the translator should view the heterogeneity in the original from the diaspora angle, and find the way to its cultural regeneration by way of the target language. So to speak, this is the cultural mission of the translator in the age of globalization. How to complete the mission of the intercultural communication? As Robertson (1992) argued, globalization usually particularizes universalism and universalizes particularism. The translator must appreciate cultural diversity, stay sensitive to cultural difference and have a diaspora perspective, that is, leaving his own cultural homeland, and then looking forward to and examining the local culture in the foreign cultural environment. While contacting and experiencing the exotic other, he is producing hybridity between cultures along with communication. In other words, the translator should first ensure himself to experience a diasporic cultural travel in translating.

\section{Translated Texts and Heterogeneous Reconstruction}

Cultural heterogeneity, or differences, refers to the uniqueness of the source language in linguistic and cultural aspects. Heterogeneousness actually contains two cases: One refers to the differences between the source language and the target language, and the second refers to the specific heterogeneity in one language. The former refers to those build-in ways of expression and cultural phenomenon in the source language compared with the target language culture, but they can be translated into the target language. The latter refers to the unique ways of language expression in the source language, but these ways of expression do not exist in the target language. Compared with the English language, the Chinese tones, the run-on sentences, and the topic sentences belong to heterogeneity. The heterogeneity discussed in this paper refers to the former.

The translator in translating, on one hand, retains some heterogeneity; on the other hand, he transforms or processes some elements in the original text, and then some new heterogeneous factors are generated. This process is also called heterogeneous reconstruction. At the same time, after these heterogeneous elements are introduced into the target language, once understood and accepted by the target language readers, they will gradually integrate the foreign culture, take root and multiply in the target culture. Thus, this communication process comes to an end. Apparently, a qualified translation does not simply involve heterogeneous transplantation, maybe grafting, or more precisely, reconstruction. As Walter Benjamin said, "richer language" is the characteristics of heterogeneous reconstruction. For instance, with astounding insight, Ezra Pound drew on the visual and paratactic functions of Chinese script in his edition of Fenellosa's essay "The Chinese Written Character as a Medium for Poetry" (1936) and in his translations of poetry and writings by Confucius. At all events, the effect of the Chinese example on Pound's own poetry is indispensable: Indeed, his imagist techniques radically transformed poetry in English and several other Western languages (Steiner, 1975). It goes without saying that this kind of reconstruction helps to promote the image building in the foreignness and also develop the English poetics. 
According to LU Xun, the primary goal of translation is to help readers read foreign works widely, make them empathize their intention and become more intellective and know more, just like travelling in foreign countries (as cited in CHEN, 2000). So translation must have an exotic flavor or a sense of foreignness (in LU Xun's term yangqi). LU Xun stood for literalism (in his term yingyi) for the purpose of keeping the spirit and force of the original text. Translation is heterozygous in essence, and a moderate hybrid translated text will arouse the reader's interest and gain their love because of its exotic characteristics.

A group of Chinese American writers live abroad all year round. Though they are native Chinese, they can fluently express their homeland's culture in idiomatic English. These diasporic writers usually use some non-standard English in writing, so a special hybrid text will be produced with a lot of Chinglish and Chinese English with local characteristics. It is evident that such texts are of characteristics with cultural hybridity. In reading their works, the influence of native culture on the thinking and ideas of diaspora people is fully seen. With the help of cultural translation, diaspora writers or translators have found an approach to connecting the maternal culture with a new cultural homeland. It is due to their special bicultural or multicultural identities that their translated texts will be characterized by heterogeneous reconstruction.

Translation is at the center of any attempt to think about questions of identity in human society. If ideology were the principal way of structured political communication, identity would take its place. This does not mean that the issues raised by ideological critics disappeared or they were not important at all, actually issues concerning marginalization, dispossession, and powerlessness are challenging the assumed position of centrality through discourses of identity. Trivedi (2005) called for translation studies to insist on the centrality of translation's polylingual aspect and to refute the generalization of cultural translation into an umbrella term for all aspects of mobility and diasporic life. Meylaerts (2006) also pointed out texts and discourses can cross so-called linguistic and cultural boundaries, disrupting the analytical pertinence of a clear-cut distinction between "sources" and "targets". Translated texts not only function in the target culture but also remain a tangible reality within the source culture.

\section{Readers and Travelling Abroad}

As is well known, translation activities involve the source and target texts, the translator, and the readers as well. Without the readers' participation, translation activity is not complete as a whole. Moreover, as Peter Newmark (2001) pointed out, "Generally speaking, translation is designed for the target language readers, though the original text is not possibly written for any readers, but merely to entertain the author himself" (p. 40). Perhaps, if the translator does not consider the readers in translation practice, the translated texts produced by him will be not popular or successful.

As to the reception theory of aesthetics, the readers often have their horizon of expectations before reading texts. Horizon of expectations refers to the potential aesthetic expectation which the readers have owned before starting to read works. Such expectation is a sort of transcendental psychological structure produced by the accumulation of the reading experience. When the reader is reading a novel, some contents in works can arouse the reader's own experience. The reader will show a greater interest in some works beyond his own horizon of expectations. The reason is that works beyond their expectations can give people an aesthetic sense of distance and freshness, even further expand the readers' horizon of expectations. As for translation, considering the 
textual fluency and readability, the translator has to adopt the strategy of domestication. However, in order to cater to the reader's horizon of expectations, the translator must effectively retain the heterogeneity of the original in the target language. As the reader comes to get more familiarity with the heterogeneous elements, he will accordingly change his attitude to literature works and heterogeneous culture in the other countries. Likewise, the translator should constantly adjust his strategies to meet the reader's psychological curiosity.

In the 21 st century, it can be an era of diaspora for more diaspora persons who stay in the foreign country, and also an epoch of wider and deeper information exchange. More and more people desire to understand the exotic culture. For the contemporary readers with a more open vision of language and culture, when they laboriously read translated texts to catch a glimpse of other or exotic cultures, the versions with diaspora can better meet their curiosity, and make the reader have a strange and fresh feeling, thus the reader will be attracted and astonished to satisfy his psychological aesthetic sense. So the reader will go beyond the boundaries of nations, ethnics, or gender, and embark on travelling in the spiritual realm. On the whole, from the diaspora perspective, the readers need to be sent abroad or to an exotic space in the process of translation, so as to satisfy their curiosity, and finally culture diaspora is completed.

\section{Translation Strategies From the Diaspora Perspective}

For a long time, in the field of translation studies, the question whether zhiyi (literal translation; word-for-word translation refers to an extreme form of zhiyi) or yiyi (sense-translation or sense-for-sense translation; free translation is misleading) is the better translation method has long troubled translation theorists. This debate, initiated by famed Buddhist monk-translators of medieval times, has lasted right up to the 20th century. It can be seen as roughly analogous to the debate in the West, since classical antiquity, on the ad verbum versus the ad sensum approach.

The Buddhist monk-translator ZHI Qian in his "Preface to the Faju jing" published in 226, quoted that, Laozi's dictum, "beautiful words are not truthful; truthful words are not beautiful", from Daode jing (Classic of the Dao), is cited to clarify the debate between fidelity to the original and artistry in translating (as cited in CHEN, 2000). Later the debate is on wen and zhi, a preference for formal resonance (xingsi) or for FU Lei's spiritual resonance. In the West, discussions on John Dryden's proposal of "metaphase (word-for-word translation)" and "imitation" and paraphrase (sense-for-sense translation), Friedrich Schleiermacher's dichotomy of "the translator leaves the writer alone as much as possible and move the reader towards him" or "he leaves the reader alone as much as possible and moving the writer towards him" (Lefevere, 1977, p. 74), and Lawrence Venuti's strategies of foreignization and domestication, have been conducted in the academia of translation for years. However, in China, translators set forth ideas on translation issues based on the way they tackled actual translation problems in their respective translation activities. Some advocate the translation method of xunyi (domestication), and others follow buxun (foreignization). Although a long period witnessed the debate, scholars such as Eugene A. Nida and P. Newmark prefer the domesticating, and scholars such as LU Xun, LIN Shu, and L. Venuti approve of the foreignizing.

SUN Zhi-li (2002) stated in his works that, "the core of foreignizing translation refers to translating the heterogeneous factors of the original, specifically, trying to retain more foreign syntactic elements, cultural meanings embedded in the source text, and the original author's particular writing techniques" (pp. 43-44). He 
predicted that in the 21 st century of China, the foreignizing strategy will continue to dominate literary translation. He strengthened his idea that priority should be given to the foreignizing strategy in literary translation and the domesticating strategy should be adopted as a supplementary method. So foreignization and domestication are not contradictory, but complementary. A culture at a given historical time is enriched and developed by means of assimilating foreign cultural elements through translation. To delight and cheer the reader up, foreignization is an important translation practice since it evokes a sense of foreignness and sends the reader abroad.

There is no denying that foreignization is directly related to authenticity, which in turn represents the cultural identity of the translated text. Undoubtedly, domesticating translation eases intercultural communication, and the purpose of reading translations is mainly to learn what is unfamiliar embedded in the foreign rather than to reinforce what is already familiar largely as a result of domestication. Thus, the target language reader is isolated from genuine intercultural dialogue with foreignness. Translational identity derives from cultural identity, whose dissolution or nullification would render intercultural communication nearly meaningless. To lend authenticity to translation, a degree of foreignization is called for.

In terms of cultural factors, apparently the foreignizing strategy should be adopted in the diaspora perspective. The foreignization strategy is enlisted to facilitate cultural communication, fulfil the reader's artistic expectation, and add more vivid expressions to enrich the target language as well. No doubt that it is direct and effective to use foreignization in expressing the differences and disseminating heterogeneity. In the meantime, it is not advisable to stiffly transplant heterogeneity. The translated texts that are bewildering and difficult to understand are inclined to kill the reader's interest in reading, let alone, exchange cultures. Thus, the diaspora cannot emerge. As mentioned above, the domestication translation strategy must be adopted as beneficial supplement. Foreignization and domestication as two strategies complement each other. In the process of translation practice, how to grasp the degree should be taken into consideration.

The cultural diaspora perspective provides a macro guiding principle for the choice of translation strategies. This principle requires the translator on one hand to adopt the foreignizing strategy to retain the exotic and heterogeneous culture; on the other hand, in order to ensure the fluency and acceptability of the translated text, to undertake appropriately heterogeneous reconstruction. LIN Yu-tang (1895-1976) as a distinguished writer and diaspora translator as well contributed much to Chinese translation theory. Thanks to his strenuous efforts, he introduced Chinese literary and philosophic traditions to the world through Chinese-English translation. He claimed himself as "Two feet between China and the Western cultures, one heart into producing universal essays". On the one hand, as a native Chinese, LIN regarded spreading Chinese culture as his own responsibility, aiming to retain and disseminate large amounts of Chinese culture; on the other hand, he was deeply influenced by the Western culture and good at examining the Chinese culture with the Westerners' eyes, because cultural elements with Chinese national characteristics were kept as "heterogeneous reconstruction" in LIN's translation, by the expression way accepted widely by the Westerners. The cultural diaspora perspective must have a profound guiding role in selecting the translation strategies.

\section{Conclusion}

The diaspora perspective demands that the translators have to stand between two kinds of culture. Such special in-between culture identity is beneficial for them to re-examine two cultures with different eyes, so that 
they have to find the intersection of two kinds of culture and gain a balanced point through translation, thus one culture will survive to some extent in another culture, even develop well, to achieve the effective intercultural communication. Translation practice from the diaspora perspective means that the translator must keep an open view, aiming to transferring the heterogeneity and promoting cultural prosperity; translated texts are a sort of heterogeneous reconstruction produced by the translator; readers are sent to travel in the foreign regions with a certain purpose, understand and experience the exotic culture there. The concept of diaspora in itself emphasizes certainly the value of foreignness or differences, and specifically it means that in the choice of translation strategies, foreignization has to occupy the main position. The diaspora perspective as a macro-guideline helps the translator get a proper selection of two strategies of domestication and foreignization. At the same time, it elicits new enlightenment: The translator should engage translation practice based on the diaspora perspective. It is of guiding significance to cultivate the qualified and competent translator in the global context.

\section{References}

Benjamin, W. (2012). The translator's task (S. Rendall, Trans.). In L. Venuti (Ed.), The translation studies reader (pp. 75-83). London and New York: Routledge.

CHEN, F. K. (2000). Zhongguo yixue lilun shigao (A history of translation theory in China) (Rev. ed., pp. 286-307). Shanghai: Shanghai Foreign Language Education Press.

Jameson, F. (1998). Preface. In F. Jameson \& M. Miyoshi (Eds.), The cultures of globalisation (pp. xi-xvii). Durham, NC: Duke University Press.

Lefevere, A. (1977). Translating literature. The German tradition from Luther to Rosenzweig (Approaches to Translation 4). Assen and Amsterdam: van Gorcum.

Meylaerts, R. (2006). Conceptualizing the translator as a historical subject in multilingual environments: A challenge for descriptive translation studies? In G. L. Bastin \& P. F. Bandia (Eds.), Charting the future of translation history (pp. 59-80). Ottawa: University of Ottawa Press.

Newmark, P. (2001). A textbook of translation. Shanghai: Shanghai Foreign Language Education Press.

Robertson, R. (1992). Globalisation: Society theory and global culture. London: Sage Publications.

Robertson, R. (1995). Globalisation: Time-space and homogeneity-heterogeneity. In M. Feather, R. Robertson, \& S. Lash (Eds.), Global modernities (pp. 25-44). London and New York: Routledge.

Robinson, D. (1995). Theorizing translation in a woman's voice. The Translator, 1(2), 153-75.

Snell-Hornby, M., Pöchhacker, F., \& Kaindl, K. (Eds.). (1994). Translation studies: An interdiscipline. Amsterdam: John Benjamins.

Steiner, T. R. (1975). English translation theory: 1650-1800. Assen and Amsterdam: van Gorcum.

SUN, Y. F. (2004). Shijiao Chanshi Wenhua (Perspective, hermeneutics and culture). Beijing: Tsinghua University Press.

SUN, Z. L. (2002). Zhongguo de wenxue fanyi: cong guihua dao yihua (China's literary translation: From domestication to foreignization). Chinese Translators Journal, 1, 40-44.

Taft, R. (1981). The role and personality of the mediator. In S. Bocher (Ed.), The mediating person: Bridges between cultures (pp. 53-88). Cambridge, MA: Schenkman.

Trivedi, H. (2005). Translating culture vs. cultural translation, 91st Meridian. Retrieved from http://www.uiowa.edu/91st/vol4-n1 /index.html

Tymoczko, M., \& Gentzler, E. (2002). Translation and power. Boston, MA: University of Massachusetts Press.

Vermeer, H. J. (1994). Translation today: Old and new problems. In M. Snell-Hornby, F. Pöchhacker, \& K. Kaindl (Eds.), Translation studies: An interdiscipline (pp. 3-16). Amsterdam: John Benjamins.

Wolf, M. (2002). The third space in postcolonial representation. In S. Simon \& P. St-Pierre (Eds.), Changing the terms: Translating in the postcolonial era (pp. 127-146). Ottawa: University of Ottawa Press. 